Article

\title{
Sustainable Move towards Flexible, Robotic, Human-Involving Workplace
}

\author{
Brigita Gajšek ${ }^{1, *(1)}$, Saša Stradovnik ${ }^{2}$ and Aleš Hace ${ }^{2}$ (1) \\ 1 Faculty of Logistics, University of Maribor, 3000 Celje, Slovenia \\ 2 Faculty of Electrical Engineering and Computer Science, University of Maribor, 2000 Maribor, Slovenia; \\ sasa.stradovnik@um.si (S.S.); ales.hace@um.si (A.H.) \\ * Correspondence: brigita.gajsek@um.si; Tel.: +386-3-428-5312
}

Received: 26 June 2020; Accepted: 12 August 2020; Published: 14 August 2020

\begin{abstract}
The realisation of the ideas of smart factories and sustainable manufacturing can be quickly realised in companies where industrial production is high-volume, low-mix. However, it is more difficult to follow trends toward industry 4.0 in craft industries such as tooling. This kind of work environment is a challenge for the deployment of sustainability and smart technologies because many stages involve the so-called "manual processing according to the worker's feeling and experience." With the help of literature review and testing in the production environment, we approach the design of a procedure for planning a sustainable technological upgrade of craft production. The best method proved to be a combination of a maturity model, process mapping with flowcharts, critical analysis, and customised evaluation model. Workplace flexibility, as a move towards sustainability, is presented in a laboratory environment on screwing performed by human wearing HoloLens and collaborative robot.
\end{abstract}

Keywords: flexibility; workplace; collaborative robot; HoloLens; sustainability

\section{Introduction}

Sustainability is, according to the International Institute for Sustainable Development (IISD), the foundation for today's leading global framework for international cooperation-the 2030 Agenda for Sustainable Development. The most commonly cited definition for Sustainable Development is from Our Common Future, also known as the Brundtland Report [1]: "Sustainable development is a development that meets the needs of the present without compromising the ability of future generations to meet their own needs." Sustainable development is defined as an approach to developing or growing by using resources in a way that allows them to renew or continue to exist for others. Taking into account the importance of sustainability, the paper considers the following critical factors for achieving sustainable workplaces: eliminating waste, saving time, and improving health.

For decades, new and emerging technologies have been addressed as a potential for sustainable development of the production sector. With proper risk management, they offer enormous opportunities for raising productivity and living standards, for improving health, and for conserving the natural resource base [1]. Recently, collaborative robots, augmented reality (AR), and automated guided vehicles (AGVs) have been rapidly adopted in production environments as new but emerging technologies. One of the objectives of their introduction in production environments is to increase workplace flexibility and, most likely, productivity $[2,3]$. Flexibility in the workplace has been defined as "the opportunity of workers to make choices influencing when, where, and for how long they engage in work-related tasks" [4]. Bal and De Lange [4] used interviews to show a range of ways in which flexible working can enhance both personal and team effectiveness. For example, flexible workers actively 'craft' their work environments to improve their efficiency. They also helped their colleagues 
and were more focused on their work. They report that managers discussed how they felt that flexible workers were more organised and productive. In the paper, we want to bring a new aspect of flexibility to the fore, namely the ability of the worker to make decisions about how much of his manual work he will hand over to some kind of technological solution, such as a collaborative robot. When he or she performs a task for the first time, the help of AR can instruct if he or she feels it is appropriate. The material or items can be moved by himself/herself or sent by an AGV. This kind of flexibility makes sense in craft industries such as toolmaking, where each product is different from the previous one. Although the workers are trained to do the work entirely by hand, some operations are physically extremely strenuous, and automation is out of the question because of expensive programming and clamping on costly machines. The solution could be sought in the so-called human-automation symbiosis work system. It includes a smart and skilled operator, also called operator 4.0, who performs not only cooperative work with robots but also work aided by machines as and if needed by means of human cyber-physical systems, advanced human-machine interaction technologies and adaptive automation [5].

The industry development can improve human conditions, although it has been degrading the natural environment. Industry activity is also influencing the social dimension-changes in the employment structure in the labor market; an increase of unemployment; digital exclusion; increase in work monotony; and marginalisation of the human role. Hence, it is necessary to strive for sustainable development, where economic growth is met without compromising the ability of future generations to meet their environmental and social needs [6].

Not all organisations can or even should implement the same set of practices [7]. The differences between individual industries can be substantial, such as differences between serial production and craft activity. The tooling industry is known for innovation and craftsmanship with little automation. Tools made for the automotive industry have to withstand the production of several million pieces that are later delivered to assembly lines. The tools produced are manufactured within narrow tolerance ranges, in a tenth of a millimeter. The toolmaking industry faces the challenge of ensuring the precision of the tools and the punctuality of delivery [8]. If European toolmakers want to keep prices higher than the competition, they have to justify them in some way. The reason should not be more expensive labor but shorter lead times or a more advanced business model. There is an urgent need to reorganise workplaces to provide technological support for employees. The automation of a particular production operation is mostly not possible and not reasonable, because the time-consuming programming of only one single product part is not economically profitable. There are very few flat surfaces on the product; the complexity of surfaces, curves, and passages is high. That is why the easiest way to make it is by hands, with experienced workers.

The paper aims to show an approach to switch from a manual to a flexible, robotic, human-involving workplace in the case of a tool manufacturer. The method includes diagnosing the digital maturity of a company, getting to know the general process model of a tool manufacturer, finding workplaces with potential for redesign, and experimenting with a workplace that has the potential for technological upgrades in a laboratory environment. The paper concludes that there is excellent potential in craft workplaces to increase productivity by adding current technologies while protecting the health of employees while maintaining the flexibility of decision-making between manual and robotic processing.

The structure of the work is as follows: Section 2 presents the Methodology and Section 3 the Theoretical background. Section 4 focuses on the case study, experimenting with methodology and testing in a laboratory environment. Section 5 discusses the results. The paper ends with conclusions.

\section{Methods}

The tooling company was chosen as an excellent example of the craft sector. In this kind of industry, digitisation and the use of Industry 4.0 are lagging behind the average. As such, it is a perfect environment for the implementation of a new type of workplace flexibility to accelerate development, which, due to the craft nature of production, is usually only in the form of modernisation of machinery. 
The business process of a general tool manufacturing company is well described in the literature. Henriques and Pecas [9], whose work formed the basis for our general model in Figure 1, wrote that production consists mainly of design, manufacturing process, tool inspection, assembly, and finally, tray removal. The adequacy of the general model was confirmed on two examples of Slovenian toolmakers. The paper focuses on the manufacturing process, or more precisely, on workplaces in the production hall. We are witnessing a project-organised production, where each produced tool is unique. A copy appears from time to time, but at least one year has passed in between.

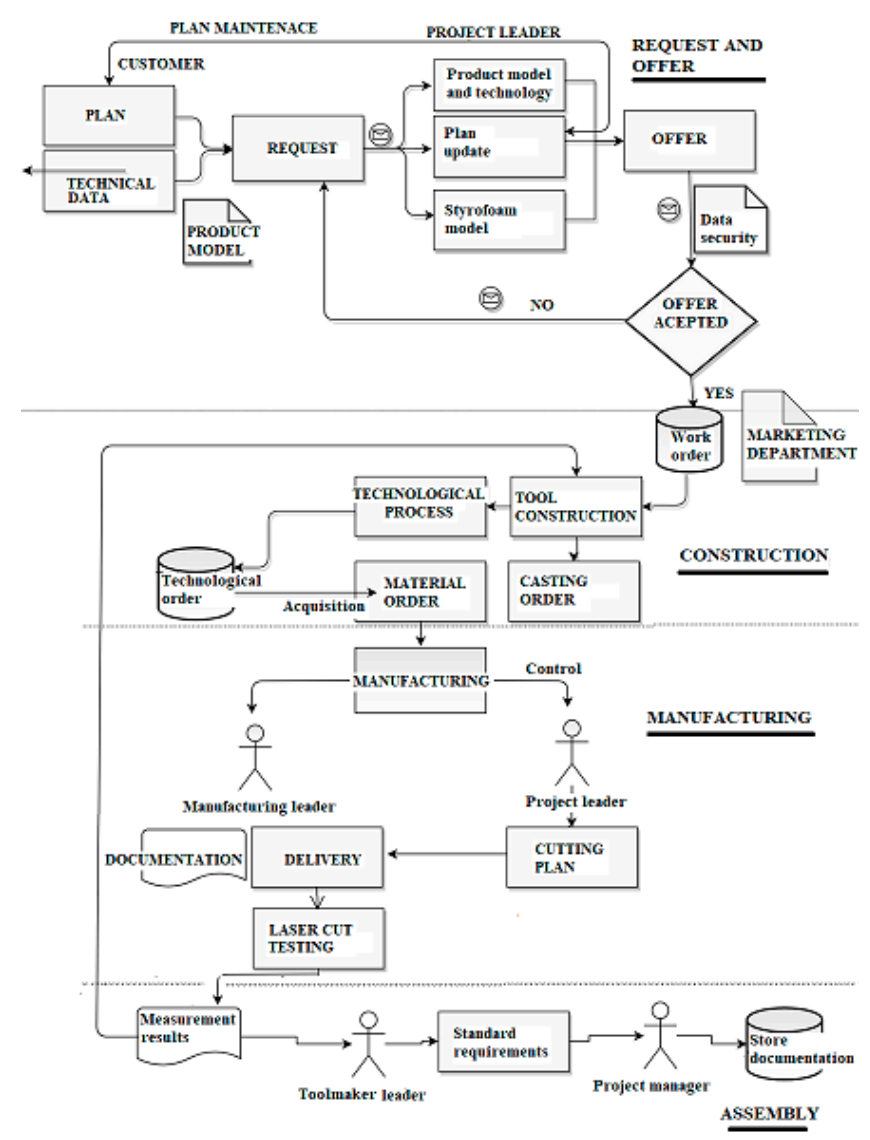

Figure 1. General business process in toolmaking (adapted from [9]).

Due to lower prices of tools on the market and ever-shorter product life cycles, tooling companies are also forced to look for internal reserves. Continuous improvements that are a mandatory element of serial production in craft production facilities are not present. Robots, smart equipment, and AGVs are technological achievements that toolmakers look with lack of interest. In practice, managers in tooling companies believe that investments in such technologies can only be recouped in series production. In this paper, we are looking for the meaning of the introduction of these technologies into the craft industry. Our research started with a literature review to be able to plan a transition from manual to a flexible, robotic, human-involving workplace. Several of the studied topics are listed in Figure 2. Results are, to a greater extent, presented in our previous works [8,10-12]. Of all, only findings on the flexible workplace, collaborative robots, AR, and Operator 4.0 are described in detail in the next section. The literature review was followed by research work in a specific tooling company, which will remain unnamed. Based on observations of employees at work and semi-structured interviews, we mapped out a production process that is carried out at several workplaces. A connoisseur of work in toolmaking production observed each employee for one hour and, in parallel, wrote down performed activities, determined the type of activities, measured time and distance travelled, and counted units. All data were entered in a flow process chart following the guidelines of the A.S.M.E. [13]. In this way, the data were collected in great detail. Observer asked workers about deviations from standard 
activities, the workplace layout, how they supply their workplace, and how the products are moved to the next workplace. Beside mandatory questions, he also asked other questions to improve his understanding of what was happening in the workplace. The observed business process in an unnamed company is identical at the highest level to that in Figure 1. The general model proved to be too broad for technological upgrade planning. The case study was mandatory to reveal the details about the manufacturing process and workplaces in the form of process maps, flow charts, and layouts. An analysis of the AS-IS state followed the process mapping.

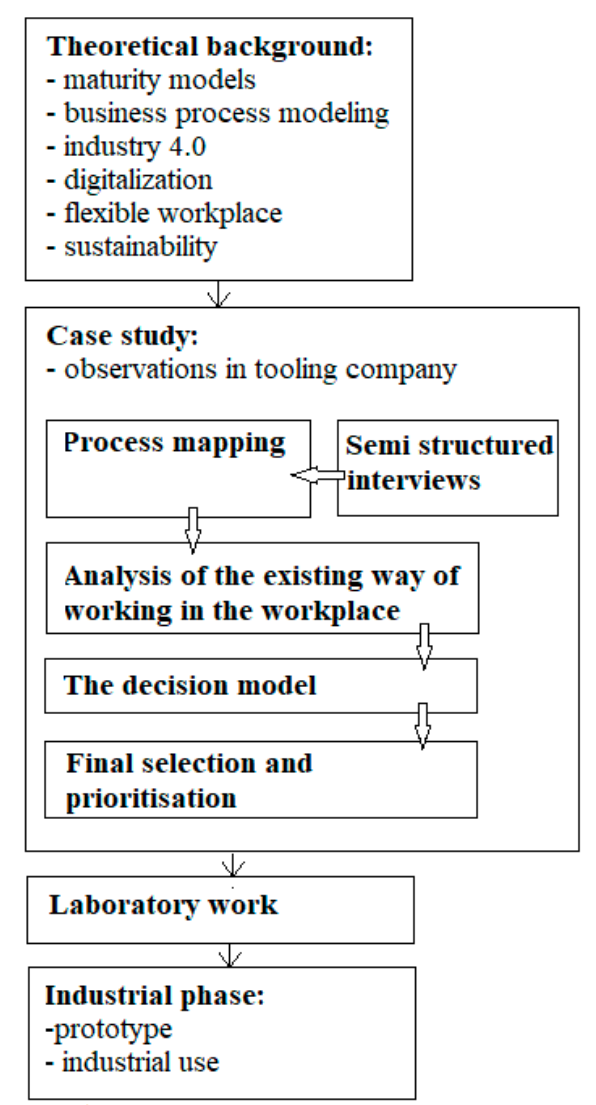

Figure 2. Methodological steps.

In the next step, the evaluation model was developed for the classification of selected workplaces with upgrading potential according to the degree of actuality for technological upgrading to progress one of them from manual to a flexible, robotic, human-involving workplace. After the evaluation, workplaces were classified according to performance characteristics and expected return on investment (ROI). A new technology scenario was created for one of the workplaces with potential. So far, a manual workplace could include a collaborative robot and an AR that could be upgraded with AGV. The idea was tested to a limited extent in a laboratory.

\section{Theoretical Background}

\subsection{Flexible Workplace}

Workplace flexibility has been defined as "the opportunity of workers to make choices influencing when, where, and for how long they engage in work-related tasks" [4]. Recent trends in the availability of flexible working arrangements (FWAs) have seen an increase in flexibility in the workplace [14]. FWAs include a variety of arrangements, which allow employees to work flexibly both in terms of when (e.g., a variable start time of the shift) and where they work (e.g., working from home). 
The professional literature suggests increasing flexibility with adjustable equipment, occupant controlled lighting, wireless connectivity, and communication tools to support the mobility of workers, which allow thermal comfort, flexible infrastructure such as walls, sitting/standing tables and, movable furniture.

As early as 1998, Gittleman, Horrigan, and Joyce [15] found that it is possible to successfully do business in the time of intensification of international competition and rapid changes in technology. They saw solutions in changes in the organisation of work, and that companies needed to become more "flexible," or to "transform" themselves, or to adopt "high performance" workplace practices to be successful. Today's FWAs were in early works named as the flexibility of an employer, which can be measured along numerous dimensions, one of these being an organisation of work. Authors [14] consider an employer to be exhibiting flexibility in the organisation of work when (in the process of producing a good or providing a service) there is a movement away from a traditional, hierarchical structure in which employees have a rigid, narrowly defined role. The introduction of some flexibility has often been associated with the introduction of new technology. It requires the acquisition of appropriate competencies by employees that work in an organised fashion with the latest technology. At the introduction of new technology, the company moves away from the traditional way of working, and the cost of experimentation, allowed flexibility, is much less than the investment in the new technology. Giving flexibility to employees mitigates the shock of change and can result in some form of innovation. Gittleman and his co-authors [15] inquired six alternative work organisation practices: worker teams, total quality management (TQM), quality circles, peer review of employee performance, employee involvement in the firm's technology and equipment purchase decisions, and job rotation.

Although the professional literature and FWAs now include a variety of arrangements that allow employees to work flexibly in terms of when and where they work, there is one overlooked or less frequently addressed aspect of flexibility. That is flexibility in terms of how and under what technological scenario the work will be done. In mass production, development has moved towards full standardisation, even of movements, to get a repetitive job done as quickly as possible. In contrast, the craft sector remains poorly technologically supported because automation is either not cost-effective or too demanding in terms of development. Also, employers avoid standardisation because it reduces creativity. However, they want the work to be done faster when possible.

Workplace flexibility in our case should not be understood as flexibility in the sense mentioned above, but rather as flexibility in the opportunity of workers to make choices influencing the mode or technological scenario of performing a task on a continuum from purely manual to purely machine-based. We have not found any similar scientific records or discussions in our literature review.

\subsection{Operator 4.0}

Romero et al. [5] introduced an Operator 4.0 typology. They explored a set of key enabling technologies for supporting the development of 'human-automation symbiosis work systems' for Operator 4.0 in the Factory of the Future. Operator 4.0 is smart, skilled, and trained to establish interaction-based relationships with machines. These relationships go beyond cooperative work with robots. Operator 4.0 has different skills from a classic machine operator. He is equipped with gadgets to realise the potentials of Industry 4.0. Operator's capabilities are improved due to the installation of sensors, collaborative robotics, navigation, data visualisation, human-in-the-loop control systems, and others. In this way, the operator takes control over the work process and the technology. According to previous research, we conclude that the Operator 4.0, equipped with the right technological equipment and skills, could be able to nuance the execution of tasks on the continuum from entirely manual to fully machine.

Over the past decades, the number of robots in European companies has been growing, which unequivocally affects the operator's profile. Robots have primarily replaced low-medium skilled workers carrying out manual and repetitive tasks rather than critical, non-routine or decision-making 
tasks [16]. As a result, there is less opportunity for human learning, in particular for low-medium skilled workers, resulting in decreasing tacit knowledge about processes and systems.

\subsection{Collaborative Robots}

To achieve high product customisation by implementing flexible and highly reconfigurable production systems, which can swiftly switch between different products of varying lot sizes, the co-existence of humans and robots seems a promising solution. It allows the sharing of workplaces, resources, and tasks [17-19]. This new type of robot is named as a collaborative robot or cobot. By combining the robot's precision, repeatability, and strength with the human's intelligence and flexibility, we can achieve an excellent synergy effect [20]. This effect is promising not only in serial production but also in small-scale production. Workers can hand over tasks that are ergonomically problematic for him/her to collaborative robots. They can take over the tasks because of the "repeatability" feature. Collaborative robots can be easily taught how to move without time-consuming programming. This technological advancement removes the barrier that made for many years impossible to reduce manual work, for example, in the toolmaking sector. Although human operator and cobot are sharing a workplace, their collaboration is limited [21], for instance, because of low payload functionality, such as strength augmentation, and highly precise positioning is not possible. Wang et al. [20] systematically research and present the state-of-the-art in the field of human-robot collaboration without denying the possibility to harmonise autonomous decisions, change levels of autonomy and responsibility, and leave more abstract decisions to humans where conscious judgement is needed.

When studying the state-of-the-art state of the use of collaborative robots in the toolmaking industry, we did not find a case study from this specific industry. However, we identified some laboratory studies of human-robot collaboration for polishing and grinding, which are also found in toolmaking. Studies mostly assume serial production rather than one-piece production, as is typical of toolmaking. Modern force-controlled robotic manipulators, in combination with additional sensor configurations [22], allow a wide range of operational scenarios for flexible production processes. The most frequently addressed challenge now and in the future is tracking curved freeform surfaces to avoid time-consuming programing. In addition to adding sensors, researchers are also testing new tools to allow the simultaneous operation of the robot system and human operator to carry out tasks cooperatively [23].

The connection between human operators and robots is becoming tight and more mundane. When robot task reconfiguration is needed, the operator must be provided with an easy and intuitive way to do it [24]. Recent research refers to the methods of instructions/knowledge transfer from a human to a collaborative robot and between robots.

Science and practice recognised several categories of human-robot collaboration [25]. Two of them are being recently introduced and require a more consistent reorganisation of the work stand [26]. The first is a situation where a robot takes a component/a tool from a human hand or a human takes a component/a tool directly from a robot. The second is a situation where a robot can be guided by manual guidance to perform the task, or can just assist human to lift heavy loads.

The development and acceptance of collaborative robots are highly dependent on reliable and intuitive human-robot interaction on the factory floor [27]. Authors use wearable sensors and inertial measurement units to capture the human upper body gestures and propose a parameterisation robotic task manager, in which according to the system speech and visual feedback, the co-worker selects/validates robot options using gestures.

To conclude, the placement of collaborative robots in a wide variety of work environments is currently a hot research topic. Many laboratory tests provide insight into the advantages and disadvantages of individual implementation alternatives. For the most part, experiments are tied to the boundary condition of serial production. Almost nothing is written about the methodological approach to the modeling of these systems. The emphasis is entirely on a technical viewpoint. 


\subsection{Augmented Reality}

Interactive human collaboration with a collaborative robot requires an intuitive communication interface. This interface can incorporate a variety of technologies by which humans interact with the robot. One of them is augmented reality technology, often referred to as one of the key technologies in Industry 4.0. Augmented reality allows adding virtual information to a real environment that is being viewed via technology [28]. This means that not only that we can see and touch our natural surroundings, but we are also able to add in virtual features, such as images, videos, and sound. It is often used for testing and studying new processes before their deployment. Novel features are being tested to allow interaction among human workers and a variety of automation systems, such as collaborative robots, a broader set of tasks (including assembly and disassembly of components), flexibility of modeling industrial processes for different domains and purposes, a clear separation of process definition and simulator, and independence of specific programming languages or technologies [9]. Research in this area is also carried out mainly in laboratory environments. However, the results are not such as to allow unambiguous transfer to other areas of application.

\section{Case Study}

\subsection{AS-IS State}

In addition to the general business process in the tooling industry (Figure 1), the classification of workplaces according to the type of work performed was recorded while capturing an AS-IS state as follows: cutting; machining; tempering; grinding and polishing; laser cutting; assembly; surface alignment and inspection. In most tool manufacturing companies, there are no multi-purpose workplaces, and the layout is functional. Items are moved between workplaces. Often they can be brought repeatedly to the same workplace. In each workplace, the primary process has been mapped with a flowchart (Figure 3). Figure 3 shows only part of the "tempering" process. The process is graphically represented at three levels of detail by following the rules for drawing flow charts. Numbers 1 and 2 at process level 2 direct the flow chart user to the appropriate place along the flow chart to read the continuation of process activities. An overview of all processes in full is not necessary for this paper, as we propose a methodology and tools. Each process and task was named with a unique ID. Processes were given IDs from P1 to P7. The specific task within a particular process (for example, P2) was identified with the task code from T1 to Tn (for example, P2.T2). The assignment of IDs is required due to electronic data processing.

The mapping showed that more than $50 \%$ of the decisions are made directly at the workplace because the prepared technology procedure defines only operation at the workplace level, such as tempering, but not individual tasks leading to a finished heat treatment.

The employees transfer most items and materials between the machines themselves. They spend at least $10 \%$ of their time checking the status of the parts they need to complete within the launched work orders at co-workers on different locations in a production hall. Two of the tasks are recognised as being particularly physically demanding, namely adjusting two adjacent surfaces and polishing. In addition to physical strength, these tasks also require repetitive movements lasting several hours, which in the long term can result in musculoskeletal disorders.

By recording the AS-IS state, the researchers familiarised themselves with the details of the production process. They found that the company is at the lowest level of digital maturity [29] and that workers are often exposed to physically strenuous, repetitive movements that can be detrimental to their health. An analysis followed. It aimed to develop a flexible, robotic, human-involving workplace, where a robot assists production workers in performing production tasks, including the use of augmented reality (AR) and having the potential to add AGV when appropriate. In the critical evaluation of the AS-IS state (Figure 4a), we analysed all tasks within the process separately for all ten workplace types. The same questions were asked for each task: Is the task routine / repetitive, ergonomically less acceptable, unnecessary, value-adding, suitable for technological upgrading, using paper documents? 
In the case of shortcomings, the potential for development towards a smart factory or industry 4.0 was described.

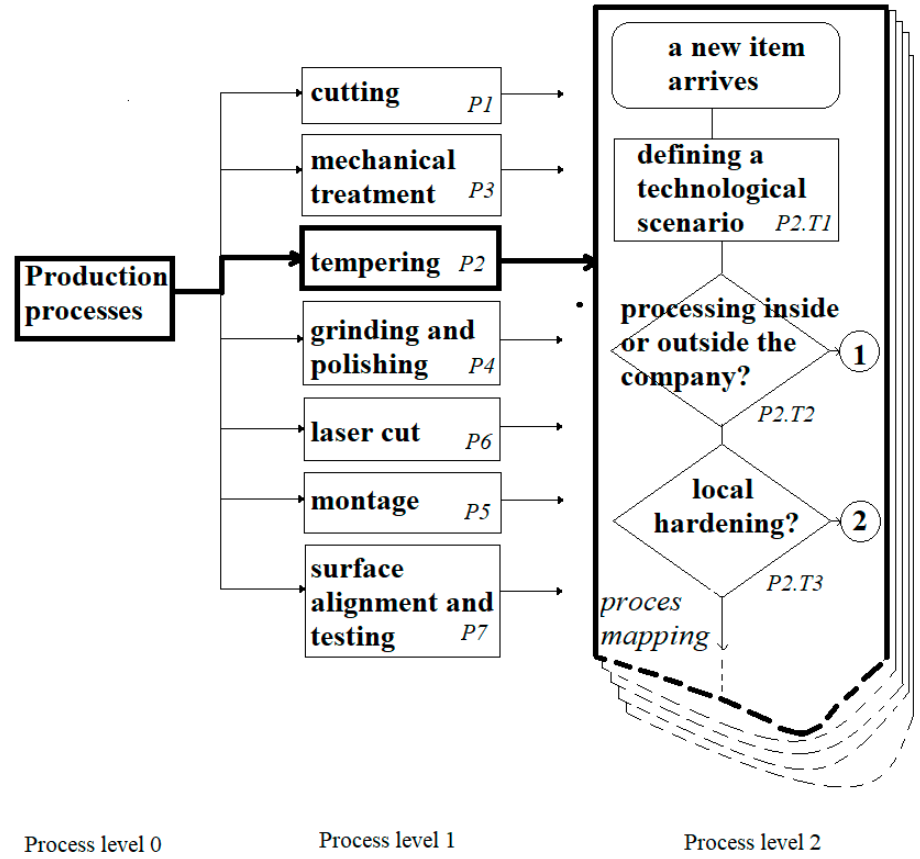

Figure 3. Process mapping.

\begin{tabular}{|c|c|c|c|}
\hline $\begin{array}{l}\text { Task ID } \\
\text { Task name }\end{array}$ & AS-IS & Poter & tial for technological upgrade \\
\hline \begin{tabular}{|l|} 
P2.T1 \\
defining a \\
technological \\
scenario
\end{tabular} & $\begin{array}{l}\text { Admission is not } \\
\text { tied to the exact } \\
\text { term, the } \\
\text { numeric codes }\end{array}$ & AGV & $\begin{array}{l}\text { AGV drives items to the } \\
\text { hardening department, drives } \\
\text { items from the hardening } \\
\text { department. }\end{array}$ \\
\hline & $\begin{array}{l}\text { are written / } \\
\text { engraved on the } \\
\text { item, the }\end{array}$ & CR & $\begin{array}{l}\text { The combination of CR and } \\
\text { AGV enables independent } \\
\text { loading / unloading of items }\end{array}$ \\
\hline & $\begin{array}{l}\text { employee's } \\
\text { expertise is } \\
\text { required to } \\
\text { make the } \\
\text { decision, worker } \\
\text { is transporting } \\
\text { items }\end{array}$ & $A R$ & $\begin{array}{l}\text { Automatic recognition of } \\
\text { numerical codes on items and } \\
\text { linking them with other data in } \\
\text { the database: priorities, } \\
\text { occupancy of hardening } \\
\text { department, deadline, ... oral } \\
\text { exchange of information is no } \\
\text { longer required. }\end{array}$ \\
\hline T. & & AGV & \\
\hline
\end{tabular}

(a)

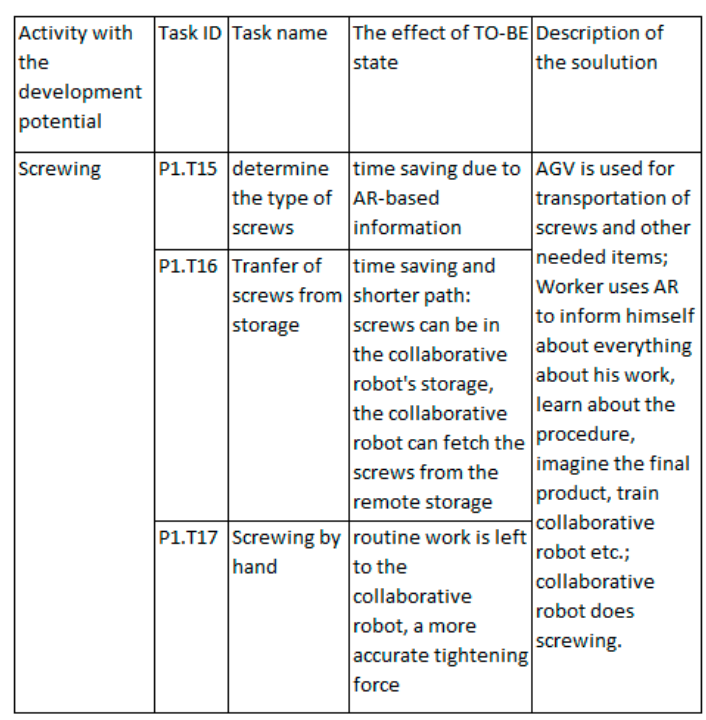

(b)

Figure 4. (a) Critical evaluation of AS-IS and described development potential; (b) Example of improvement proposal in the early phase.

For each workplace, similar tasks were combined with a synthesis within a single line of the proposal to improve the AS-IS state towards a flexible, robotic, human-involving workplace. For this purpose, a long list of possible improvements has been identified as a starting point for decision making at a higher level of decision making. One line of such a proposal is shown in Figure $4 \mathrm{~b}$.

Analysis of AS-IS state resulted in 10 suggestions for improvement with the potential for a flexible, robotic, human-involving workplace:

- correction of the surface of the plate holders,

- micro-forging, 
- local manual inductive welding,

- loading of a machine with simple square workpieces,

- screwing in the assembly phase,

- 3D shape scanning,

- applying data to the surface of tool components,

- production and usage of measuring devices,

- inserting bolts on the press table,

- internal transport within the production hall.

\subsection{Evaluation Model}

Out of 10 proposals for improvement with the potential for a flexible, robotic, human-involving workplace, some had to be selected for laboratory testing. To this end, an evaluation model was developed to classify the proposals according to the degree of actuality for the development of technological support. The criteria are presented in the form of a complex table. The table consists of six separate evaluation sections, namely:

- potential for a flexible, robotic, human-involving workplace (partially presented in Figure 5),

- analysis of the technical aspect,

- developmental analysis,

- analysis of the economic issue,

- analysis of the aspect of humanisation of work,

- final evaluation using weights.

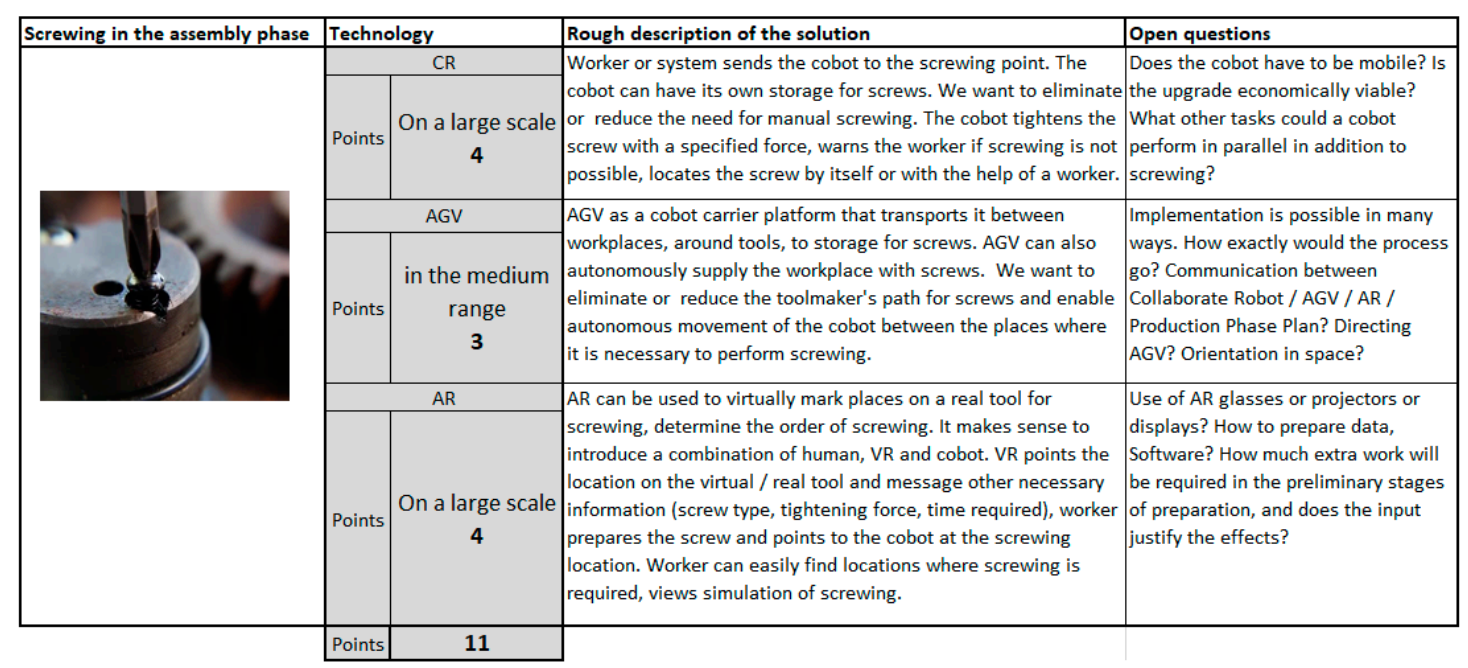

Figure 5. A part of an evaluation model. CR, collaborative robot; AGV, automated guided vehicle; AR, augmented reality.

For example, we will explain the concept of evaluation in a section "potential for a flexible, robotic, human-involving workplace." For each of the ten proposals for improvement, the possibility of upgrading by each one of three technologies was identified, namely Collaborative Robot (CR), Augmented Reality (AR), and Automated Guided Vehicle (AGV). For this purpose, rough descriptions of the conceptual design for each improvement proposal were prepared according to all three technological solutions, as shown in Figure 5 for screwing in the assembly phase. The open questions were also recorded, which will be answered during the project. For each type of technological solution (CR, AGV, AR), the potential for upgrading from manual to a flexible, robotic, human-involving workplace was evaluated using a six-step evaluation scale. Possible answers to the question "Is there a potential for upgrading?" were: 
- 0 -not likely,

- 1 -from $1 \%$ to $20 \%$ of the task,

- 2-from $21 \%$ to $40 \%$ of the task,

- 3-from $41 \%$ to $60 \%$ of the task,

- 4 -from $61 \%$ to $80 \%$ of the task,

- 5-from $81 \%$ to $100 \%$ of the task.

The answer "not likely" is given 0 points. At the same time, the evaluated suggestion for improvement is eliminated from the decision-making process, since the technological upgrade is impossible.

The following questions were used to evaluate the technical aspect:

- Ability to achieve lower, equal or improved productivity over the existing procedure?

- Flexibility versus flexibility in the current procedure?

- Quality versus quality in the current procedure?

- Possible degree of automation reached?

- Possible level of collaboration reached?

- Are object masses suitable for a technological upgrade?

- Are object shapes suitable for a technological upgrade?

- Is the size of the available work area suitable for a technological upgrade?

The following questions were used to evaluate the developmental aspect:

- What is the estimated degree of complexity of solution development?

- What is the estimated actuality of the solution in 5 to 10 years?

- The following questions were used to evaluate the economic aspect:

- What is the estimated cost of development?

- What is the estimated cost of manufacturing?

- Is ROI acceptable?

The following questions were used to evaluate the aspect of humanisation of work:

- Will be workers relieved in terms of inappropriate posture?

- Will be workers relieved in terms of repetitive movements?

- Will the solution enhance workplace safety?

An essential evaluation mechanism is a final evaluation using weightings. This means that we can add different weights to the previously mentioned aspects depending on the requirements/opinions of the client. Each aspect can thus be regulated by a weighting mechanism in the overall evaluation. In our case, the most important aspects were the potential for flexible, robotic, human-involving workplace, technical aspect, and economic aspect. The result of the evaluation was one of the reasons for the laboratory development of screwing using a collaborative robot and augmented reality.

\subsection{The Laboratory Development of Screwing Using a Collaborative Robot and Augmented Reality}

Collaborative robot applications bring new possibilities for the automation of manufacturing processes. That is true even if conventional full automation is not possible or economically viable. The latter is mainly present in case of small and medium enterprises with low-volume, high-mix production that requires a flexible and cost-efficient manufacturing approach or for craft businesses such as the toolmaking industry. Furthermore, fully automated processes, which may require high engineering costs for complex solutions, often do not offer sufficient flexibility, even with today's technological capabilities. The involvement of humans in the collaborative process with robots can lead to better adaptability of the task in a low structured environment through human skills, intelligence, 
creativity, perception, and decision-making ability, which are hardly competitive with the current state of technology. As a result, the robot task and thus also the production technology can be significantly simplified in collaborative human-robot manufacturing since humans can easily do the cognitively more demanding part. However, most current collaborative applications are quite inefficient due to several reasons, including some limitations related to flexibility and intuitive interaction and communication in human-robot collaboration. In [10], a laboratory collaborative robot application of screwing is presented with the concept of the advanced user interface by holographic augmented reality (HoloLens), which efficiently addressees the latter problem. The robot application is based on the idea of a hybrid workstation, where humans can actively collaborate with the robot by sharing the workspace while performing a common screwing task (Figure 6).

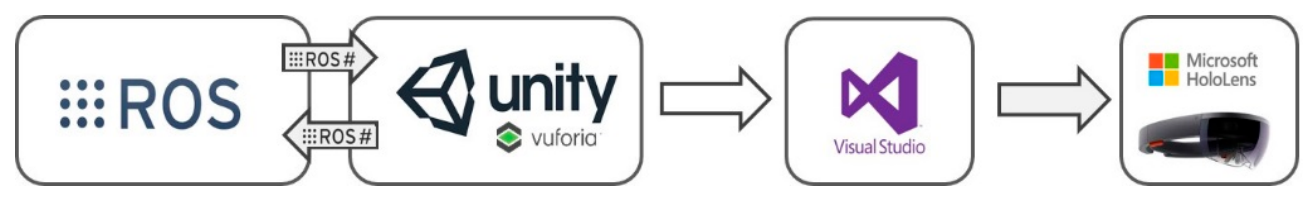

Figure 6. Design of augmented reality application with HoloLens.

In contrast to the classical handheld screwing, where the human is responsible for the successful completion of all necessary steps, our collaborative screwing application allows a division of these tasks between robot and human worker (Table 1). Tasks division is based on the capabilities and availability of both concerning the critical analysis of the technological process.

Table 1. Division of tasks between human and robot.

\begin{tabular}{lcc}
\hline \multirow{2}{*}{ Task } & \multicolumn{2}{c}{ Executor } \\
\cline { 2 - 3 } & Human & Robot \\
\hline Screw insertion & $\checkmark$ & \\
Screwing & $\checkmark$ & $\checkmark$ \\
Torque measurement & & $\checkmark$ \\
\hline
\end{tabular}

The human worker inserts screws into the prepared holes, performs a visual inspection, and removes damaged or unsuitable screws, which is relatively simple and effortless for the human. For this reason, no additional accessories are required for sorting, aligning, and dosing the screws to a screwdriver, as it is necessary with fully automated screwing systems. Most physically demanding and repetitive tasks can be left to the collaborative robot, freeing the human worker from monotonous, dull, and harmful workloads, which are the leading cause of worker fatigue. The decision on how much help the worker needs from the collaborative robot can be made intuitively through an interactive interface. The interface is based on holographic augmented reality technology and Microsoft HoloLens glasses, which enables to overlay computer-generated digital 3D visual information on the real world. The 3D virtual objects created by Unity3D can be further anchored and can superficially interact with the real environment in real-time. The use of AR markers allows the spatial alignment of the virtual objects in relation to the real environment and their objects. Recognition and tracking of AR markers are made possible by the Vuforia library, which can be included in the Unity software environment.

To integrate the HoloLens into the robotic system, we used a robot operating system ROS that combines software libraries and tools that can help in the development of such robot applications. Communication between Unity3D and ROS is established via the ROS\# library, which allows the exchange of information between ROS publishers and subscribers. The communication between robot UR3e and ROS is enabled using the WebSocket protocol, through which we send the screwing sequence and the position of new screwing points. For the development of our laboratory application, we have established a connection between UR3e-ROS-HoloLens (Figures 6 and 7). 


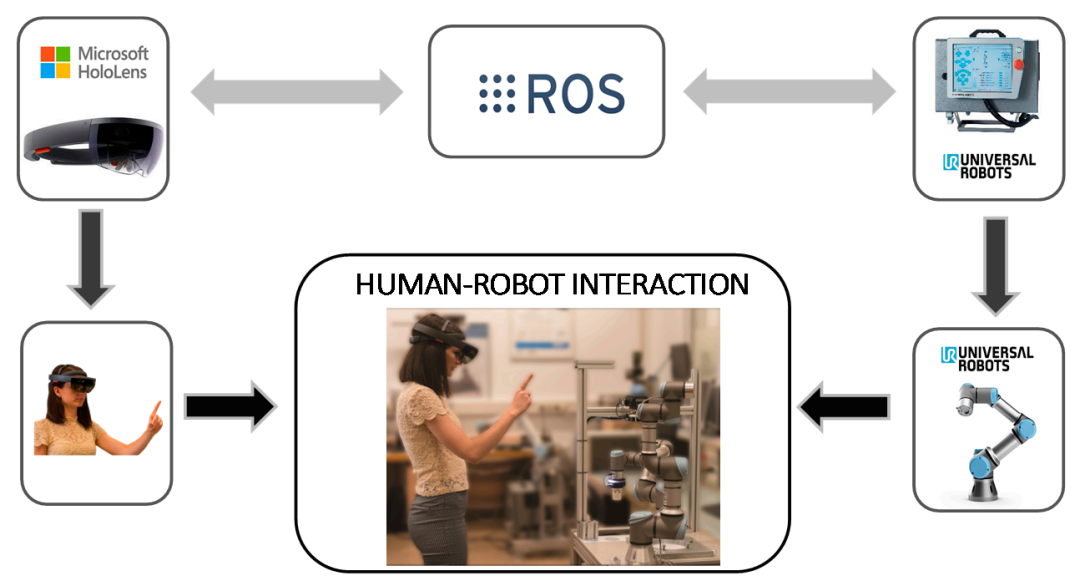

Figure 7. Structure of augmented reality application with HoloLens.

This user-friendly holographic interface enables the robot task to be parametrised flexibly and intuitively. The worker can choose which screws have to be screwed by a collaborative robot and which by the human. At the same time, the worker can also schedule the sequence of the screwing execution. This can be done with gaze targeting specific screw and selecting it by gesture interaction, as shown in Figure 8. In addition, the validation of the defined robot trajectory with the simulation by the virtual robot in its real workspace can also be performed via the holographic interface (Figure 9). In this way, the correction of the screwing sequence, the feasibility of the robot trajectory from the reachability point of view, and the robot singularities can be checked. In contrast to the simulation in an off-line robot programming software, the augmented reality simulation allows us to check collisions in the real robot environment and add additional waypoints to prevent them. After a successful virtual simulation, the robot program can be executed on the real robot.

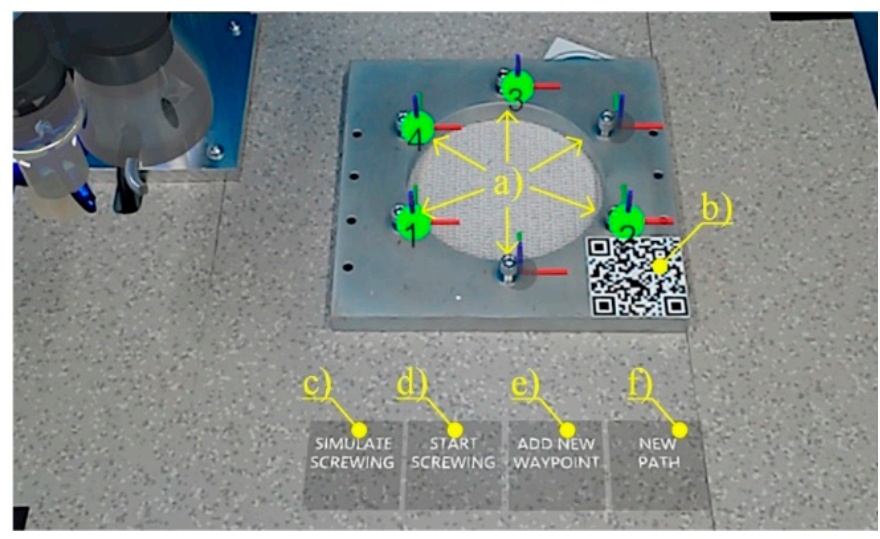

Figure 8. AR interface: (a) virtual buttons for screwing location selection; (b) AR marker; (c) virtual button for the beginning of robot screwing simulation; (d) virtual button for the beginning of screwing on the real robot; (e) virtual button for adding new waypoint; (f) virtual button for new path generation.

During the execution of robot screwing, the worker can also use an intuitive physical interface that allows direct physical interaction between robot and human. It is designed to ensure human safety in the collaborative robotic application according to the technical specification ISO/TS 15066, which permits sharing workspace between human and robot, hand-guiding operation, and requires power and force limiting. This allows a worker to screw or perform other work near robot when it is in the operational phase. The collision detection allows safe stopping the robot or temporarily interrupt the screwing cycle. Temporarily interruption may be needed to adapt the robot task by kinesthetic learning if the robot detects a deviation from the predicted screwing sequence (e.g., missing screw), which could prevent the successful execution of the robot task. 


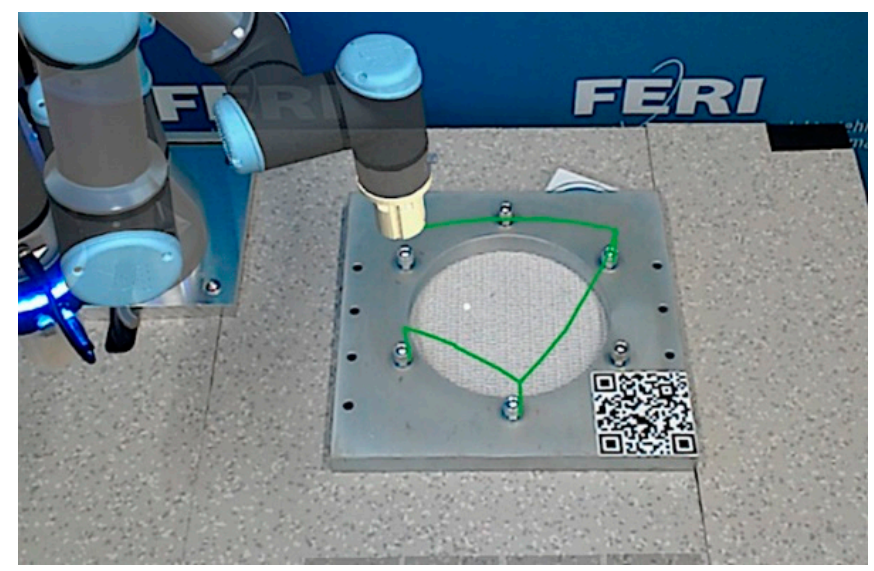

Figure 9. Holographic virtual 3D model of robot UR3e during the simulation.

Developed laboratory solution allows the employee in extreme option to do the work independently and without robot, AR, or AGV support, although technological solutions are at his/her fingertips. Flexibility is an employee's option to choose between manual procedure and technical support on a continuum from $0 \%$ to $100 \%$.

Although we were looking in the analytical or selection phase for a workplace that would also have the potential to introduce AGV, we did not develop and test this kind of technological upgrade in the laboratory environment due to the lack of equipment in the laboratory.

\section{Discussion}

The paper deals with the rarely discussed area of a technological upgrade in the tooling sector. This area is specific due to features such as craftsmanship, one-piece flow, functional layout, customer-specific development, and engineering to order (EtO) manufacturing, low level of automation, and much more. In this environment, the introduction of new technologies is a significant challenge. The introduction of new technologies requires a high financial outlay, which is difficult to justify for this specific type of production financially. These circumstances do not improve over time, on the contrary. The transfer of even a small share of physical and routine work certainly has a long-term impact on employee well-being. However, the importance of maintaining health is only gaining on the importance that the financial aspect already has. Globalisation is leading to a drastic reduction in the prices that customers are willing to pay for new tools. A shorter life cycle of cars and other products also shortens the delivery times for new tools. The application of the modularity principle requires a longer tool life because it is used for several types of cars. The drop in profits does not have a positive effect on the willingness of tool manufacturers to invest in digitalisation and new technologies. Somehow, they are pushed to develop by changed characteristics of a workforce that is on average older, unwilling to perform repetitive and routine work, and wants to use information technology. Significant workers' motivating factor can be that they feel that they can plan their work execution. Innovations that drive the success of tooling companies over decades are often the result of teamwork, so work in such factories should not change in the direction of automatisation and preventing communication between workers with their isolation in a specific workplace. They should communicate more when, for example:

- new problems arise during the production and assembly phase;

- inadequate products are produced by a particular tool;

- new ideas are required to achieve the prescribed tolerances;

- extremely demanding curves have to be produced, etc.

The paper suggests some of the benefits that the introduction of new technologies could bring to a tooling company. The introduction of new technologies certainly increases sustainability, 
as technologically equipped workplaces produce less waste, save time, and maintain health. Repetitive work has a negative impact on the well-being of workers. Quite a few activities in the tooling process take hours and require either forced postures or great physical effort or both. To identify these activities and evaluate their potential for technological improvement, a tooling company carried out a process mapping exercise using process charts and flowcharts. The activities within the processes were explained based on semi-structured interviews with employees. Extremely strenuous is the activity of smoothing contact surfaces, which have a very varied surface and cannot be polished by machine. In addition to this activity, we found several others. For example, screwing is also a routine activity, which is characterised by the need to observe the tensile force. There is a lot of walking between workplaces, as most items are carried around manually. Employees walk from one workplace to another to check the work status for items they need to finish.

The employees themselves, based on handwritten symbols on the items, make decisions on detailed production. It is difficult to replace an individual employee, as only he or she knows most of the information, experience, and knowledge about a particular job. Following the results of the critical analysis, we have identified 10 proposals for improvement that have the potential for a shift from manual to the flexible, robotic, human-involving workplace, which requires gradual implementation. For prioritisation, we have designed an evaluation model to classify the proposals according to the degree of actuality for the development of technological support. Although we wanted to build a simple model, we had to consider five evaluation aspects or evaluation sections. When deciding where a new technology should be used, we propose to take into account the degree of suitability for the introduction of a particular technology, as well as technical, developmental, economic, and humanisation aspects. We found that not all aspects are equally important to the company, so the model had to allow for the possibility of weighting individual aspects. The proposed methodology is suitable for any company looking for the potential for technological upgrades within its business processes and workplaces. Although we tried to make a decision based on maturity models alone [11], this approach proved to be too imprecise. The best method proved to be a combination of the maturity model, process mapping with flowcharts, critical analysis, and customised evaluation model. The main contribution of the paper is the detailed demonstration of a successful methodology for planning the introduction of new technologies in atypical manufacturing environments. The second contribution of the paper is the proposal for research and the development of ignored workplace flexibility. We develop through research and laboratory testing the possibility for the worker to choose how much of his/her manual work he/she will leave to some kind of technological solution. We are considering three technological solutions that attract the most attention today and are complementary. The central executive role takes over a collaborative robot, which is demonstrated in the presented laboratory application of collaborative screwing with the help of AR by HoloLens. The proposed robotic system, which incorporates advanced technologies such as AR, is a good solution for increasing the efficiency and flexibility of complex production systems in craft industries such as toolmaking, where each product is different from the previous ones. Although the workers are trained to do the work entirely by hand, some operations are physically extremely strenuous, and automation is out of the question because of expensive programming and time-consuming clamping. However, this type of collaborative approach helps us to achieve lower investment costs and reduce the time required for system integration compared to the traditional full robotisation. The use of this concept enables better adaptability of the robot task in an intuitive way that does not require additional robot programming skills.

\section{Conclusions}

The collaborative nature, the ability to learn, and the guarantee of a safe co-existence of collaborative robots and humans in the shared workspace represent an essential change in the use of robots. Robots are penetrating mass production relatively quickly, while it is economically challenging to accommodate them in craft enterprises such as the toolmaking industry. It is, therefore, particularly important that 
the right methodological approach is taken when considering the technological upgrade of a manually managed workplace to a flexible, robotic, human-involving workplace. The best methodology proved to be a combination of the maturity model, process mapping with flowcharts, and critical analysis [30], rounded in content with a customised evaluation model. Further studies on the flexibility of workplaces combining collaborative robots, AR, and humans are proposed and presented in the laboratory case study on collaborative screwing by HoloLens programming.

Author Contributions: Conceptualization, B.G.; methodology, B.G. and A.H.; laboratory development, S.S. and A.H.; validation, B.G., S.S., and A.H.; formal analysis, B.G. and A.H.; investigation, B.G., S.S., and A.H.; writing—original draft preparation, B.G. and S.S.; writing—review and editing, B.G. and A.H.; supervision, A.H. All authors have read and agreed to the published version of the manuscript.

Funding: This research was funded by the Republic of Slovenia and the European Union from the European Regional Development Fund, ROBOTOOL-1 project, grant number OP20.03540.

Conflicts of Interest: The authors declare no conflict of interest. The funders had no role in the design of the study; in the collection, analyses, or interpretation of data; in the writing of the manuscript, or in the decision to publish the results.

\section{References}

1. World Commission on Environment and Development. Our Common Future; Oxford University Press: Oxford, UK, 1987; Available online: http://www.un-documents.net/our-common-future.pdf (accessed on 27 April 2020).

2. Bauer, T.K. Flexible Workplace Practices and Labor Productivity. 2003. Available online: https://papers.ssrn. com/sol3/papers.cfm?abstract_id=382842 (accessed on 26 June 2020).

3. Van Der Voordt, T.J.M. Productivity and employee satisfaction in flexible workplaces. J. Corp. Real Estate 2004, 6, 133-148. [CrossRef]

4. Bal, P.M.; De Lange, A.H. From flexibility human resource management to employee engagement and perceived job performance across the lifespan: A multi-sample study. J. Occup. Organ. Psychol. 2014, 88, 126-154. [CrossRef]

5. Romero, D.; Stahre, J.; Wuest, T.; Noran, O.; Bernus, P.; Fast-Berglund, Å.; Gorecky, D. Towards an operator 4.0 typology: A human-centric perspective on the fourth industrial revolution technologies. In Proceedings of the International Conference on Computers and Industrial Engineering (CIE46), Tianjin, China, 29-31 October 2016; pp. 29-31.

6. Hoffa-Dabrowska, P.; Grzybowska, K.; De Souza, J.P.E. Sustainable Supply Chain: A content analysis based on published case studies. in press.

7. Mrugalska, B.; Wyrwicka, M.K. Towards lean production in industry 4.0. Procedia Eng. 2017, 182, 466-473. [CrossRef]

8. Radić, I.; Rupnik, B.; Šinko, S.; Kramberger, T.; Gajšek, B. Redesign of the Workplace for Toolmakers towards Industry 4.0. In Handbook of Research on Integrating Industry 4.0 in Business and Manufacturing; Karabegović, I., Kovačević, A., Banjanović-Mehmedović, L., Dašić, P., Eds.; IGI Global: Hershey, PA, USA, 2020; pp. 492-511.

9. Ottogalli, K.; Rosquete, D.; Amundarain, A.; Aguinaga, I.; Borro, D. Flexible Framework to Model Industry 4.0 Processes for Virtual Simulators. Appl. Sci. Basel 2019, 9, 4983. [CrossRef]

10. Stradovnik, S.; Pučko, R.; Hace, A. Interaktivna laboratorijska aplikacija s kolaborativnim robotom in holografskim vmesnikom mešane resničnosti HoloLens na primeru vijačenja. Ventil 2019, 25, 378-386.

11. Sternad, M.; Lerher, T.; Gajšek, B. Maturity levels for logistics 4.0 based on NRW's industry 4.0 maturity model. In Business Logistics in Modern Management, Proceedings of the 18th International Scientific Conference Business Logistics in Modern Management, Osijek, Croatia, 11-12 October 2018; Dujak, D., Ed.; Josip Juraj Strossmayer University of Osijek, Faculty of Economics in Osijek: Osijek, Croatia, 2018.

12. Henriques, E.; Peças, P. New business models for the tooling industry. In Advances in Business and Management; Nelson, W.D., Ed.; Nova Science Publishers: New York, NY, USA, 2012.

13. American Society of Mechanical Engineers. Special Committee on Standardization of Therbligs, p. Charts. A.S.M.E. Standard Operation and Flow Process Charts; The American Society of Mechanical Engineers: New York, NY, USA, 1947. 
14. Clarke, S.; Holdsworth, L. Flexibility in the Workplace: Implications of Flexible Work Arrangements for Individuals, Teams and Organisations; ACAS: London, UK, 2017; pp. 1-52. Available online: https://archive.acas.org.uk/media/4901/Flexibility-in-the-Workplace-Implications-of-flexible-work-arrangementsfor-individuals-teams-and-organisations/pdf/Flexibility-in-the-Workplace.pdf (accessed on 26 June 2020).

15. Gittleman, M.; Horrigan, M.; Joyce, M. "Flexible" Workplace Practices: Evidence from a Nationally Representative Survey. ILR Rev. 1998, 52, 99-115.

16. Ansari, F.; Hold, P.; Mayrhofer, W.; Schlund, S.; Sihn, W. Autodidact: Introducing the Concept of Mutual Learning into a Smart Factory Industry 4.0. In Proceedings of the 15th International Conference on Cognition and Exploratory Learning in Digital Age, Budapest, Hungary, 21-23 October 2018; pp. 61-68.

17. Chryssolouris, G. Manufacturing Systems: Theory and Practice; Springer: New York, NY, USA, 2006.

18. Michalosa, G.; Makrisa, S.; Tsarouchia, P.; Guaschb, T.; Kontovrakisa, D.; Chryssolourisa, G. Design considerations for safe human-robot collaborative workplaces. Procedia CIRP 2015, 37, 248-253. [CrossRef]

19. Michalos, G.; Makris, S.; Spiliotopoulos, J.; Misios, I.; Tsarouchi, P.; Chryssolouris, G. ROBO-PARTNER: Seamless Human-Robot Cooperation for Intelligent, Flexible and Safe Operations in the Assembly Factories of the Future. Procedia CIRP 2014, 23, 71-76. [CrossRef]

20. Wang, L.; Gao, R.; Váncza, J.; Krüger, J.; Wang, X.V.; Makris, S.; Chryssolouris, G. Symbiotic human-robot collaborative assembly. CIRP Ann. 2019, 68, 701-726. [CrossRef]

21. Bechtsis, D.; Tsolakis, N.; Vlachos, D.; Iakovou, E. Sustainable supply chain management in the digitalisation era: The impact of Automated Guided Vehicles. J. Clean. Prod. 2017, 142, 3970-3984. [CrossRef]

22. Amersdorfer, M.; Kappey, J.; Meurer, T. Real-time freeform surface and path tracking for force controlled robotic tooling applications. Robot. Comput.-Integr. Manuf. 2020, 65, 1-15. [CrossRef]

23. Perez-Vidal, C.; Gracia, L.; Sanchez-Caballero, S.; Solanes, J.E.; Saccon, A.; Tornero, J. Design of a polishing tool for collaborative robotics using minimum viable product approach. Int. J. Comput. Integr. Manuf. 2019, 32, 848-857. [CrossRef]

24. Carfi, A.; Villalobos, J.; Coronado, E.; Bruno, B.; Mastrogiovanni, F. Can Human-Inspired Learning Behaviour Facilitate Human-Robot Interaction? Int. J. Soc. Robot. 2020, 12, 173-186. [CrossRef]

25. Helms, E.; Schraft, R.D.; Hagele, M. rob@work: Robot assistant in industrial environments. In Proceedings of the 2002 IEEE International Workshop on Robot and Human Interactive Communication, Berlin, Germany, 25-27 September 2002; pp. 399-404.

26. Stadnicka, D.; Antonelli, D. Human-robot collaborative work cell implementation through lean thinking. Int. J. Comput. Integr. Manuf. 2009, 32, 580-595. [CrossRef]

27. Neto, P.; Simão, M.; Mendes, N.; Safeea, M. Gesture-based human-robot interaction for human assistance in manufacturing. Int. J. Adv. Manuf. Technol. 2019, 101, 119-135. [CrossRef]

28. Çolak, O.; Yünlü, L. A Review on Augmented Reality and Virtual Reality in Engineering Education. J. Educ. Instr. Stud. World 2018, 8, 1-8.

29. Gajšek, B. Approach for the systematic transition of the company into industry 4.0. In Business Logistics in Modern Management, Proceedings of the 19th International Scientific Conference, Osijek, Croatia, 10-11 October 2019; Dujak, D., Ed.; Josip Juraj Strossmayer University of Osijek, Faculty of Economics in Osijek: Osijek, Croatia, 2019.

30. Gajšek, B.; Marolt, J.; Rupnik, B.; Lerher, T.; Sternad, M. Using maturity model and discrete-event simulation for industry 4.0 implementation. Int. J. Simul. Model. 2019, 18, 488-499.

(C) 2020 by the authors. Licensee MDPI, Basel, Switzerland. This article is an open access article distributed under the terms and conditions of the Creative Commons Attribution (CC BY) license (http://creativecommons.org/licenses/by/4.0/). 